\title{
Who Will Establish a Proper Data Model for Family Medicine and Primary Care?
}

\author{
Larry A. Green, MD
}

The policy brief in this issue ${ }^{1}$ used recent data concerning published accounts of primary care workforce innovations to contrast the way questions were formulated and the grants and interventions designed for National Institutes of Health (NIH)-funded studies versus studies based on routine practice. The majority of NIH-funded studies focused on diseases, biomedical data, and adherence to requirements of the research design. In contrast, innovating practices typically focused on plausible solutions to practice problems, given local conditions and constraints. Critical contextual factors in practices were ignored in many NIH-funded studies. The practice-based, contextualized approach tended to yield results that were easier to implement and sustain in practice. To quibble about the precision of the contrasts is to miss the point of this brief, which contemporizes a persistent, stubborn problem for primary care as a function and family medicine as a discipline. Given the importance of expanding usable knowledge to improve practice, these findings matter.

In the policy brief, Etz et $\mathrm{al}^{1}$ recommend that the NIH alter some of its research policies to place higher value on contextual learning and change the way studies about practice innovation are evaluated, along with the measures they use to do so. This situation, a contest in which advocates "es-

Submitted 25 June 2014; revised 25 June 2014; accepted 25 June 2014.

From the Department of Family Medicine, University of Colorado, Denver.

Funding: none.

Conflict of interest: LAG is an editorial board member of the $7 A B F M$.

Corresponding author: Larry A. Green, MD, Department of Family Medicine, University of Colorado School of Medicine, Mail Stop F496, Academic Office 1, 12631 East 17th Avenue, Aurora, CO, 80045 (E-mail: Larry.Green@ucdenver.edu).

\section{See Related Article on Page 738.}

pouse competing understandings of reality and the nature of knowledge and struggle in various realms to achieve validation . . . for their styles of reasoning," is not news in general or in family medicine and primary care in particular. ${ }^{3-6}$ While research policymakers would do well to act immediately on this brief's recommendations, perhaps family medicine and primary care should recognize again that instead of external factors, conditions internal to the discipline and primary care may play a dominant role in underachievement. ${ }^{7}$ One serious internal deficiency within family medicine and primary care is the lack of an agreed on, proper data model that helps organize what is studied and how it is studied.

A data model can be thought of as a description of the objects to be represented in a system, their properties and interrelationships, and the subject(s) of interest. Such a model contains a collection of concepts, involves classification, and requires rules be used in dealing with the model. The contrasts declared in this policy brief reflect the use of different underlying data models by the NIH and innovating practices. The NIH model seems to be clearer than family medicine's.

Innovating practices and family medicine academicians could turn their gaze toward articulating a proper data model fit for their purposes, to good effect. Episodes of care organized around individuals of all ages and families; the quality of therapeutic relationships; team functionalities; linkage of practices with public health; and the integration of primary care practices with mental health, subspecialty medicine, and care at home and in institutions are examples of what could be included in the family medicine and primary care data model. This is not virgin territory, as previous collaborative conferences $^{8}$ and the International Classification of Primary Care ${ }^{9}$ confirm. The timeliness of an aggressive focus on this basic work is suggested by keen national interest in "big data." ${ }^{10-12}$ Its plausi- 
bility is supported by the vision of the Office of the National Coordinator for Health Information Technology and its investment of billions of dollars into data systems. ${ }^{13}$ Its feasibility is supported by widespread, ongoing work to establish data standards (content, architecture, transport, security, vocabularies, stewardship) that permit interoperability and patient protection across care settings and within communities, becoming learning systems for health. ${ }^{13-15}$

This policy brief is important because it uses contemporary data to reconfirm longstanding, serious research problems impeding the discovery and innovation necessary to achieve affordable, better health care that yields better health—the central focus of health policy in the United States today. Policy briefs aim to use contemporary data to stimulate thinking about important issues and thereby generate movement to address them. This one succeeds and challenges research funders and practicebased investigators to collaborate to clarify frameworks and methods and make some changes in research policy to enable rapid improvements of clinical practices serving millions of people each day. How might family medicine and the rest of primary care seize this opportunity and challenge? Who can establish a proper data model to unite and guide the discovery of family medicine and primary care?

\section{References}

1. Etz RS, Hahn KA, Gonzalez M, Crabtree BF, Stange KC. Practice-based innovations: more relevant and transportable than NIH-funded studies. J Am Board Fam Med 2014;27:738-9.

2. Whooley O. Knowledge in the time of cholera: the struggle over American medicine in the nineteenth century. Chicago (IL): University of Chicago Press, 2013.
3. Green LA, Fryer GE Jr. Family practice in the United States: position and prospects. Acad Med 2002;77:781-9.

4. Nutting PA, Green LA. Practice-based research networks: reuniting practice and research around the problems most of the people have most of the time. J Fam Pract 1994;38:335-6.

5. Fraser I, Lanier D, Hellinger F, Eisenberg JM. Putting practice into research. Health Serv Res 2002;37: xiii-xxvi.

6. Stange KC, Miller W, McWhinney I. Developing the knowledge base of family practice. Fam Med 2001;33:286-97.

7. McWhorter JH. Losing the race. Self-sabotage in Black America. New York: Simon and Schuster; 2000.

8. Phillips RL, Klinkman M, Green LA. Conference report: harmonizing primary care: clinical classification and data standards. Washington, DC: The Robert Graham Center; 2007. Available from: http:// www.graham-center.org/online/etc/medialib/graham/ documents/publications/mongraphs-books/2007/ rgcmo-harmonizing-primary.Par.0001.File.tmp/classification.pdf/. Accessed June 2014.

9. ICPC-2: The International Classification of Primary Care. Geneva: World Health Organization; 1987 [updated March 2003]. Available from: http://www. who.int/classifications/icd/adaptations/icpc2/en/. Accessed June 2014.

10. Schneeweiss S. Learning from big health care data. N Engl J Med 2014;370:2161-3.

11. Kush R, Goldman M. Fostering responsible data sharing through standards. N Engl J Med 2014;370: 2163-5.

12. Psaty BM, Breckenridge AM. Mini-sentinels and regulatory science-big data rendered fit and functional. N Engl J Med 2014;370:2165-7.

13. HealthIT.gov [homepage on the Internet]. Available from: http://www.healthit.gov/. Accessed June 2014.

14. National Committee on Vital and Health Statistics [homepage on the Internet]. Available from: http:// www.ncvhs.hhs.gov/. Accessed June 2014.

15. The Folsom Group. Communities of solution: the Folsom Report revisited. Ann Fam Med 2012;10: 250-60. 